\title{
Sacral neuromodulation for bowel dysfunction
}

\author{
J.-L. Faucheron · G. Martin
}

Received: 8 May 2013/Accepted: 15 May 2013/Published online: 6 June 2013

(C) Springer-Verlag Italia 2013

Bowel dysfunction generally refers to a variety of clinical conditions including fecal incontinence, constipation, and chronic pelvic pain.

Fecal incontinence is the uncontrolled loss of stool, either liquid or solid. Its true prevalence in the adult population is unknown, but might be as high as $5 \%$ if based on a Cleveland Clinic score above 5/20 [1]. The resulting handicap is responsible for social isolation and reduced quality of life. First treatment should be dietary measures, medication, and biofeedback physiotherapy. Surgery is indicated when conservative treatment fails. Direct sphincter repair is suggested in the case of limited total sphincter rupture, but results deteriorate over time, with only around $50 \%$ of patients still continent at long-term follow-up. Sphincter substitution is indicated in patients with large sphincter defects or a severely disrupted sphincter and in the case of failure of other surgical treatment. Non-stimulated graciloplasty (the so-called Pickrell's procedure) has been abandoned because of the fatigability of the transposed muscle [2]. Dynamic graciloplasty is nowadays very rarely proposed in the treatment of fecal incontinence because the technique is complex, expensive and has a high morbidity rate [3]. Despite a certain level of expertise, our results with the artificial bowel sphincter, like other authors have recently shown, are less promising than those previously published in the literature [4].

Sacral nerve modulation, first developed for the treatment of urinary dysfunction, is another option that has proved to be effective in the treatment of fecal

J.-L. Faucheron $(\bowtie) \cdot$ G. Martin

Colorectal Unit, Department of Surgery, University Hospital,

CS 10217, B.P. 217, 38043 Grenoble Cedex, France

e-mail: JLFaucheron@chu-grenoble.fr incontinence in patients with an intact or nearly intact sphincter complex [5]. Some authors have demonstrated that sacral neuromodulation could also be beneficial in patients with sphincter defects, in patients presenting with fecal incontinence following anterior resection and chemoradiation for rectal cancer, and in patients suffering from systemic sclerosis or Crohn's disease. After implantation, $41-75 \%$ of patients achieve complete fecal continence and 75-100 \% experience improvement in episodes of incontinence [5]. A few studies have also reported efficacy of sacral neuromodulation in patients suffering from double incontinence, the urinary incontinence being due to either urge incontinence (involuntary urine leakage following urgency), stress incontinence (involuntary urine leakage during efforts), or mixed (associating both urge and stress incontinence) $[6,7]$.

These functional results are obtained with a reasonable, moderate level of complications $[8,9]$. We published the number and causes of reoperation from a series of 87 consecutive patients operated on in a single institution. Among these patients, 36 had surgical revision of the device for the following reasons: device-related failure due to infection in 4 (successful reimplant in 4), electrode displacement in 2, electrode breakage in 2 (reimplantation of electrode in 4), and dysfunction owing to impedance increase in the system in 4; adverse stimulation with pain in 7 (stimulator repositioning in 4 and explantation in 3); battery depletion either spontaneously $(n=6)$ or owing to an MRI examination $(n=2)$; total or partial loss of clinical efficacy in 9 (removal of the generator and electrode). In total, nearly $40 \%$ of patients needed a revision of their stimulator, but some of the reoperations were due to the learning curve, the patients in question having been the very first patients being included in the study. A position statement, based on a collective experience of French 
experts (the NEMO club), was published with the final goal of improving technical and functional results of sacral neuromodulation in fecal incontinence [10].

More recently, applications for sacral neuromodulation have been found in the treatment of chronic, intractable severe constipation [11], and in the treatment of chronic pelvic pain [12], with encouraging results. The minimally invasive nature of the procedure and the possibility of testing the four sacral roots under local anesthesia before implantation of the stimulator in case of a positive response constitute advantages of the technique of sacral neuromodulation over other technical procedures. A prospective multicentric randomized controlled trial with crossover arms is in progress in France in order to confirm, or not, the efficacy of sacral neuromodulation in patients with chronic intractable constipation.

An Italian group of surgeons experienced in sacral neuromodulation reviewed patient selection criteria, etiology of bowel dysfunction, investigations, test and implantation procedures, follow-up and evaluation of results, and achieved an algorithm for patient management, showing the place of sacral neuromodulation in the treatment of bowel dysfunction. The recommendations are published in this journal issue and can be considered as international guidelines, to be taken into account by the major implantation centers [13].

Conflict of interest Prof. Faucheron has relevant financial relationships with Medtronic as a speaker at symposia and as a consultant. Dr. Martin has no disclosure to make.

\section{References}

1. Damon H, Schott AM, Barth X et al (2008) Clinical characteristics and quality of life in a cohort of 621 patients with faecal incontinence. Int J Colorectal Dis 23:845-851
2. Faucheron JL, Hannoun L, Thome C, Parc R (1994) Is fecal continence improved by nonstimulated gracilis muscle transposition? Dis Colon Rectum 37:979-983

3. Madoff RD, Rosen HR, Baeten CG et al (1999) Safety and efficacy of dynamic muscle plasty for anal incontinence: lessons from a prospective, multicenter trial. Gastroenterology 116: 549-556

4. Darnis B, Faucheron JL, Damon H, Barth X (2013) Technical and functional results of the artificial bowel sphincter for treatment of severe fecal incontinence: is there any benefit for the patient? Dis Colon Rectum 56:505-510

5. Gallas S, Michot F, Faucheron JL, Club NEMO et al (2011) Predictive factors for successful sacral nerve stimulation in the treatment of faecal incontinence: results of trial stimulation in 200 patients. Colorectal Dis 13:689-696

6. Leroi AM, Lenne X, Dervaux B et al (2011) Outcome and cost analysis of sacral nerve modulation for treating urinary and/or fecal incontinence. Ann Surg 253:720-732

7. Faucheron JL, Chodez M, Boillot B (2012) Neuromodulation for fecal and urinary incontinence: functional results in 57 consecutive patients from a single institution. Dis Colon Rectum 55:1278-1283

8. Faucheron JL, Voirin D, Badic B (2010) Sacral nerve stimulation for fecal incontinence: causes of surgical revision from a series of 87 consecutive patients operated on in a single institution. Dis Colon Rectum 53:1501-1507

9. Faucheron JL, Herault MC (2012) Life threatening haemorrhage after electrode removal: a severe complication following sacral nerve stimulation procedure for the treatment of faecal incontinence. Colorectal Dis 14:e133

10. Leroi AM, Damon H, Faucheron JL, Club NEMO et al (2009) Sacral nerve stimulation in faecal incontinence: position statement based on a collective experience. Colorectal Dis 11: 572-583

11. Ortiz H, De Miguel M, Rinaldi M, Oteiza F, Altomare DF (2012) Functional outcome of sacral nerve stimulation in patients with severe constipation. Dis Colon Rectum 55:876-880

12. Falletto E, Masin A, Lolli P et al (2009) Is sacral nerve stimulation an effective treatment for chronic idiopathic anal pain? Dis Colon Rectum 52:456-462

13. Falletto E, Ganio E, Naldini G, Ratto C, Altomare DF (2013) Sacral neuromodulation for bowel dysfunction: a consensus statement from the Italian group. Tech Coloproctol. doi: 10.1007/s10151-013-1002-2 